\title{
A Study on Guidance Needs of Urban and Rural Adolescence In Relation To the Home Environment
}

\author{
R. Kannammal \\ Research Schalor Bharathiar university Coimbatore
}

\begin{abstract}
Adolescence is the transitional stage of development between childhood and adulthood, representing the period of time during which a person experiences a variety of biological changes and encounters a number of emotional issues. Adolescence is the period characterized by physical and psychological changes in the age group of 10-19 years. Adolescents, due to developmental crisis, are prone to face a myriad of psychosocial challenges. Psychosocial disorders are categorized into substance abuse, internalizing disorders and externalizing disorders and are prevalent in 20-33\% of adolescents. Psychosocial problems may lead to maladjustment to family, school, and peer as well as result in various psychiatric morbidities such as anxiety, depression, personality disorders in adulthood. Thus it is imperative to identify these psychosocial problems and treat appropriately in early phases.
\end{abstract}

Key Words: Guidance, Adolescence

\section{Introduction}

The idea of education is not merely to impart knowledge to the pupil in some subjects but to develop in him those habits and attitudes with which he can successfully face the future. Peter Worsely says a large part of our social and technical skills are acquired through deliberate instruction which we call education. It is the main waking activity of children from the ages of five to fifteen and often beyond. In the recent years education has become the major interest of some sociologists. As a result a new branch of sociology called Sociology of Education has become established.

Durkheim conceives education as the socialization of the younger generation. He further states that it is a continuous effort to impose on the student ways of seeing, feeling and acting which he could not have arrived at spontaneously.

\section{The Classification of Student Kingdom}

The five broad categories are the complete classification and many other sub categories can be discovered and the students be placed under suitable category/classification.

Type -1.

The common habitats of this category comprise seats near those of the opposite sex or any seat which makes them conspicuous in the class. Most common features include fashionable dressing and sporting of famous apparel brands and trendy looks. Characteristic behaviors of this include regular smoothing of hair with their hands, subconscious touching of dress or earrings, chirpy manner of talking and too much gesticulation with their hands. Rarely the brightest students in the class, they are still found to respond to questions in the class in various ways; wisecracks, giggles and laughter, usually addressed to the opposite sex. When given a test they can often be found to assume a troubled countenance, dawdling with their pen absent-mindedly and giving a carefree shrug or smile of negation when being asked the answer. Part of them, they cannot wait for the class to be over so that they can crack jokes among friends, make plans of going out with their classmates.

Type -2.

In contrast, these are shabbily dressed, usually found in the most inconspicuous corner of the class where they can evade the teacher's eye, and are often the quietest in the class. The distinctive features include a marked lack of communication skills often accompanied with a garbled attempt at speaking, a perpetual blank look while looking at the blackboard, a steady look at the notebook when the teacher is asking questions, a sincere jotting-down of everything a teacher says and a regular barrage of the dumbest questions asked on the most obvious parts of lessons. Usually, asks teacher to repeat again. When a teacher asks if students have any doubts type - 2 are the first ones to ask questions, usually irrelevant.

Type - 3

These students can be found frequenting the first or the last row of the class. Common features include a careless but neat sense of dressing, friendly manners, a concentrated look towards the blackboard and quick 
responses to questions posed in the class. Usually studies the course material before coming to the class, asks penetrating questions and can often be found correcting the teacher during the lecture. The only common trait they have in common with Type -2, is that both wait after the class to talk to the teacher, Among the top scorers in the class, Type -3 are the first to answer the questions and submit the assignments.

\section{Type -4.}

Display characteristics of both the previous. Common features include a positive interest in the class, variation in performance depending on the topic, and pronounced group behaviour. They can often solve the easier questions posed by the teacher but have to enlist help of the teacher or for solving difficult ones. They are mostly shy creatures and the level of participation in the class may vary from average to zero depending on the proximity. The ones sitting near, can often found to be active in the class while those sitting away and without friends are found to be so adept at camouflage that they can go unnoticed by the teacher in the jungle for a long period of time.

Type - 5

Easy to identify by their big physical stature and coarse manner of speaking. While members of other types usually display a respectful behaviour towards the teacher, but this type act surly and insolent towards the teacher and try to disrupt the class routine. Always answering the teacher's question with a cheeky remark or another question, they resist every attempt of the teacher to make them study. In a highly mutated, a bullying attitude towards other, can also be found. They are often the last to arrive in the class.

\section{Parental Guidance}

Parents serve as models for their child to imitate. The parent who uses physical aggression in punishing his child is serving as an aggressive model. The child, through imitation, may be acquiring aggressive response patterns although he is seemingly being taught that aggression is bad. It is not surprising then that it has been found that the severity of parental punishment for aggression is associated with the child's own display of aggression.

Children many times pick up their aggressive behaviour in school, on the playground, from friends. A factor that can lead to an aggressive child is having a parent who uses loud outbursts or violence to control the child. The child sees this as "normal" behaviour and learns that this type of behaviour is acceptable, when in today's society it is unacceptable behaviour. The best way to predict if a child will be an aggressor is to observe his early behaviour. Behavioural theorists emphasize that behaviour is a result of a process of learning from observing. What actions pay off and what works. This theory simplifies human behaviour by neglecting the biological aspects and other significant factors influencing our behaviour.

Genetic and biological theories of aggression both have strong points as well as weak points. Causation is not well established in genetic theories. If it is found that one gene exists in aggressive individuals and not in non-aggressive individuals it is not determined if the genetic information causes aggression or if aggression causes a change in genetic information. Biological theories are strong in that the choice of treatment is obvious and it has been shown to be effective. Genetic theories' weakness is that it does not explain every case of aggression. These theories also put the responsibility within the individual. The bottom line of biological theorists is that a person's environment does not affect his aggressiveness. Aggression can be learned in other ways, such as through modelling and imitation. Both biological theories and behavioural theories have some weaknesses due to the fact that they do not have immense amounts of research to support them. The theories do not effectively explain the development of aggression in children.

There will always be one side who says there is a certain factor that causes aggression, while the opposing side will give a completely different cause. Many people believe that humans are violent because we are naturally and unavoidably aggressive. This widely held theory provides us with harmful expectations, selffulfilling prophesies, and with excuses for being aggressive. The good news is that the evidence shows that humans can in the right circumstances and with appropriate training be kinder to one another. The bad news is that thus far, we seem to be losing the battle against violence. We are all exposed to a myriad of responses to frustration, but in many ways the message again is: aggression gets results.

Guidance in practice: the parents' perspective

Guidance needs

- Parents wanted to know and trust their child's guidance teacher whom they saw as responsible for his or her welfare in the school, to be able to contact and be contacted by guidance staff at appropriate times, to be kept informed of their child's progress and to be assured ofconfidentiality. 
- Regular information about their child's progress was a critical issue for parents. They wanted more, and earlier, information not only about their child's academic progress but about his or her personal and social development. They requested earlier and more detailed reports, wanted to be alerted as soon as any problems arose but also wanted contact about positive matters as well as about difficulties.

- Parents identified a range of guidance needs of their children: individual support and someone to talk to about personal problems; information and advice about careers and subject choice; help in understanding and dealing with issues relating to drugs, alcohol and sex; and support in coping with exam and study pressures. Some parents saw a need for guidance to fulfil an advocacy role for pupils within schools. The size and location of the school, the extent of its catchment and the level of deprivation in the area all influenced parents' perceptions of their child's guidance needs.

Behavioral management for middle-aged children should reflect their need for independence while still offering plenty of guidance. Even though children between the ages of 5 and 10 should be developing better control over their emotions, they are often known to display dramatic behaviors. Behavioral management for middle-aged children requires consistency and patience as they tend to test limits and can become easily sidetracked.

\section{Routines and Structure}

Oftentimes, providing simple structure will prevent a host of behavioral issues. Establish a schedule for your child, and be clear with your expectations. A regular routine can reduce noncompliance and arguments over homework, chores and electronics. Structure can also teach good habits as kids become used to doing what is expected of them. Create a clear list of rules and review the rules with your child. As your child grows and matures, adjust the rules to reflect age-appropriate responsiblities.

\section{Praise and Attention}

Although middle-aged children can be rebellious, they tend to also seek approval. The American Academy of Pediatrics' "Guide to Effective Discipline" suggests providing attention to increase positive behavior and "ignoring, removing, or withholding parent attention to decrease the frequency or intensity of undesirable behaviors." Ignoring mild misbehaviors, such as whining, can be effective as long as there is not an underlying cause that is impacting your child's behavior. If you suspect that your child is responding to a stressor in his life, do not ignore his behavior. Instead, seek out the root of the behavior. Your child should also receive positive attention for good behaviors. Praise your child's efforts, positive attitudes and compliance, and he will naturally be motivated to repeat those behaviors.

\section{Rewards}

Rewards provide middle-aged children with an incentive to manage their behaviors. Provide your child with a small allowance for completing his chores, and he'll be motivated to do them again. Offer small rewards to address behavioral issues. A child who struggles to get his homework done each night might need some external motivation. Allowing him to earn time to play his favorite video game for completing his homework might just be the incentive he needs.

\section{Natural and Logical Consequences}

Breaking the rules should result in clear consequences. Logical consequences should be clearly related to the offense. If a child refuses to get out of bed on time, a logical consequence would be an earlier bedtime. Middle-aged kids can also benefit from natural consequences. If a child refuses to wear boots on a rainy day, the natural consequence is that his feet will get wet. Monitor natural consequences to ensure that such events become learning experiences.

Some children have behavior problems because of their poor social skills, while others have poor social skills because their behavior problems prevent them from practicing social skills with friends. Good social skills are crucial to success in life, as they help us know what to say, how to make good decisions, and how to behave in many situations, says the National Association of School Psychologists.

\section{The identification of pupils' guidance needs}

There was a lack of any sustained attempt in the project schools to evaluate pupils' guidance needs. None conducted a regular, comprehensive review. Most of the staff interviewed had much relevant experience to draw on but it is important to recognise the limitations of personal experience. Guidance of parents focused on guidance provision and duties at the various school stages as much as directly identifying pupils' needs. Their response reflected a similar focus in national and regional documentation. Pupils' guidance needs might be divided into those created by schools' organisational requirements and pupils' own self-generated needs. The 
guidance system appeared, on balance, to support the smooth running of the school rather than fulfil an advocacy role on behalf of pupils.

\section{Issues}

- There is a need for more systematic and comprehensive assessment of childrens' needs.

- Is there currently an over emphasis on defining provision and needs by stage of schooling that hampers guidance staff from considering individual needs?

-What is the correct balance between guidance serving the administration of the school and supporting pupils?

\section{Provision and needs}

Guidance at home was based on a generalised model of children's needs. There was little evidence of the impact of particular pupils' needs on the nature and structure of guidance provision in each home. Some direct relationship was evident with socio-economic background. Pupils' socio-economic background was one of the major sources of variation in pupils' needs within and across the schools. Deprivation was seen as having an impact on pupils' needs and this influenced provision in a number of respects. Guidance teachers did not identify particular needs experienced by middle class pupils but they may well have had unmet needs. The attitude of staff to the socio-economic background of pupils reinforced the view of guidance as problem driven

\section{The management of guidance}

The management of guidance is a weak area and this partly a ccounted for the importance of the parents in determining pupils' experience of guidance. Although the selection and training of individuals are important, the majority of guidance teachers could be enabled to be more effective if they were better managed.

Guidance may be a more difficult or, at least, a different management task than that of a subject department. But another critical factor is the attitude of some senior managers and many parents to the contribution of management to the guidance process. There seemed to be a feeling among many staff that more attention to management would detract from the caring, personal emphasis of guidance. At its most extreme, the attitude was that the application of management principles takes time away from pupils and detracts from the guidance process. Senior managers need training in managing guidance but, more generally, attitudes to the management of guidance need to change.

The type of guidance structure, horizontal or vertical, was not a major explanatory factor in differences in the quality of guidance provision across homes. The guidance of parents in the development of management decisions varied across the homes.

\section{Guidence Needs Of Adolescence (In Rural And In Urban)}

Guidance covers the whole process of education which starts from the birth of the child. As individuals need help throughout their lives, it is not wrong to say that guidance is needed from the cradle to the grave. Guidance is as old as the human civilization. In the primitive society, elders in the family offered guidance to the young and to persons in distress. Even today, in India, guidance, whether in educational, vocational or personal matters, is sought from family elders. Guidance unorganized and informal in all places and at all levels has been a vital aspect of the educational process. With the passage of time, revolutionary changes have taken place in the field of agriculture, industry, business and medicine. These changes in all walks of life coupled with extraordinary growth in our population has made the social structure very complex. The head of the family or leader of the community with a limited knowledge of the changed conditions is hardly competent in providing guidance and counselling to the youth of today.

The term guidance is related to all types of education formal, non formal and informal, where the aim is to help the individual to adjust to his/her environment in an effective way. It can also be said that guidance is given to individuals in making appropriate choices and adjustments.

Guidance has been defined from different points of view. Guidance has been conceptualized as a programme of activities which has provided us with the gateway out of the existing numerous problems in our present age of complex scientific and technological development (Okobiah and Okorodudu 2004). The UNESCO module on guidance and counselling (2000) also posited that Guidance is a programme of services to individuals based on their needs and the influence of environmental factors. Guidance and counselling is a professional field which has a broad range of activities, programmes and services geared towards assisting individuals to understand themselves, their problems, their school environment and their world and also to develop adequate capacity for making wise choices and decisions.

Various studies have been conducted on guidance and its varied needs by many Indian and Western educationists. It is evident from these researches that most of the research work done on guidance and its varied needs has been done in western countries. In India, comparatively less work has been done. From the studies, it is evident that, guidance and counselling leaves a positive effect on the academic achievement of under 
achievers. Career guidance develops higher career maturity. Guidance needs are influenced by the intelligence level of the students. There is a difference in the vocational interests of the socio-economically advantaged and non - advantaged students. Nicholas (2002) revealed lectures and professional help outside the university as the preferred sources of guidance for first year university students. Wright (2005) identified social class, gender, ethnicity and academic attainment as key factors involved in the complex process of choices that young pupils make during their 14 - 19 transition.

Pius et. al. (2007) highlighted the importance of using assessment instruments to identify students' counselling needs. Giovazolias (2010) revealed that those students who face psychological difficulties had negative attitude towards counselling. Eyo et. al. (2010) revealed that students' attitude at secondary school stage towards guidance and counselling was significantly positive and that the gender and school location significantly influenced students' attitude towards guidance services. Guidance is the bedrock for achieving self - actualization. It is a process of helping individuals to understand themselves by discovering their own needs, interests and capabilities in order to formulate their own goals and make plans for realizing those goals.

An analysis of guidance needs of secondary school students is of paramount importance; hence this study. Guidance involves the difficult art of helping boys and girls to plan their own futures wisely in the full light of all the factors that can be mastered about themselves and about the world in with they are to live and work. Naturally, therefore, it is not the work of a few specialists, but rather a service in which the entire school staff must co-operate under the guidance of some persons with special knowledge and skill in this particular field. Guidance in this sense is not confined to the vocational only. It covers the whole gamut of youth problems and should be provided in an appropriate form at all stages of education through the co-operative endeavour of understanding parents, teachers, head masters, principals and guidance officers.

\section{Guidance and Counseling}

The terms guidance and counselling have been loosely or interchangeably used. Guidance is a term which is broader than counseling and it includes counseling as one of its services. Butter makes a logical separation of the counseling process i.e.

(i) adjustive and (ii) distibutive phase. In the adjustive phase, the emphasis is on social, personal and emotional problems of the individual, in the distributive phase the focus is upon educational, vocational and occupational problems. The distributive phase can be most aptly described as gu idance while the adjustive phase can be considered as description of counselling.

\section{Principles of Guidance}

Guidance is based upon the following principles.

(i) Holistic development of individual : Guidance needs to be provided in the context of total development of personality.

(ii) Recognition of individual differences and dignity: Each individual is different from every other individual. Each individual is the combination of characteristics which provides uniqueness to each person. Similarly human beings have an immense potential. The dignity of the individual is supreme. dignity.

(iii) Acceptance of individual needs: Guidance is based upon individual needs i.e. freedom, respect,

(iv) The individual needs a continuous guidance process from early childhood throughout adulthood.

(v) Guidance involves using skills to communicate love, regard, respect for others.

\section{Need For The Study}

Guidance is needed wherever there are problems. The need and importance of guidance are as follows.

Self understanding and self direction: Guidance helps in understanding one's strength, limitations and other resources. Guidance helps individual to develop ability to solve problems and take decisions. Optimum evelopment of individual. Solving different problem of the individual Academic growth and development, Vocational maturity, vocational choices and vocational adjustments, Social personal adjustment

Better family life Good citizenship, for conservation and proper utilization of human resources For national development Guidance is helpful not only for student and teacher in an educational institution but also to the parents, administrators, planners and community members.

So the investigator has chosen this topic for the research.

\section{Significance Of The Study}

The atmosphere of the home has much to do with student guidance. The setting should be appealing, with attention given to varying the physical features and the schedule to prevent boredom in both the parents and the children. Parents should let children know specific do's and don'ts: which are expected or desired and 
which will not be tolerated. Then parents must consistently reinforce the desired guidance while ignoring or in some other way extinguishing the undesirable ones.

Some parents make too many rules, and the children, confused or frustrated, ignore them. Parents should establish only a few rules and should specify the consequences for not following them.

Guidance can be defined as a technique that decelerates the frequency of a behavior when it is given contingent on that behavior. Reprimands, frowns, reminders and other subtle expressions can serve as punishment, and can be very effective when used appropriately.

Parents can take away the opportunity to obtain reinforcement, attention, or a portion of some event contingent on target behavior. These three procedures are also known as timeout, extinction, and response cost. Timeout can involve physically removing a student for short periods from the reinforcing event or area. Ignoring tantrums is a withdrawal of attention that may lead to extinction of the problem behavior. Taking away tokens or points for disobeying rules is an example of response cost.

\section{Personal:}

The areas of guidance are very vast. The following are some of the important areas of guidance.

Students face many personal problems related to themselves, their parents and family, friends and teachers, etc. They often have memories related to home or family which creates feeling of disappointment in them. If their parents are expecting too much of them it leaves them with a feeling of incompetence and insecurity leading poor self concept and self esteem. The objectives of personal guidance are to help the individual in his/her physical, emotional, social, rural and spiritual development.

The aims and objectives of personal guidance are:

To assist the individual in understanding himself/herself.

To assist the individual involving in their personal problems and to assist the individual into a king independent decisions and judgement.

To assist the individual to view the world and the social environment in right perspective.

To assist the individual in making sound adjustments to different problems confronted in life. Personal guidance is necessary at all stages of life.

At the elementary school stage opportunities should be given to students for their self expression. Personal guidance at this stage deals with the problems related to feeling of insecurity, social acceptance, discipline etc. At the secondary stage, the students have more intricate personal problems. During the secondary stage adolescent students due to peculiar physical, emotional and social developments undergo noticeable changes in their attitude and behaviour. Personal guidance at this stage should therefore focus on personal and social adjustment. Personal guidance at the tertiary stage aims at helping them view life in relation to reality. The scope of personal guidance at this stage is very wider.

Educational Guidance: If one closely examines the problems of young pupils in schools and colleges, one would exactly realize the need of educational guidance. Educational problems head the needs of students problems. So education is an important guidance area.

Educational guidance is related to every aspect of education school / colleges, the curriculum, the methods of instruction, other curricular activities, disciplines etc. Educational guidance is the assistance given to the individual (i) to understand his/her potentialities (ii) have a clear cut idea of the different educational opportunities and their requirements (iii) to make wise choices as regards to school, colleges, the course : curricular and extra curricular. Some of the aims and objectives of educational guidance are: To assist the pupil to understand him/herself i.e. to understand his/her potentialities, strength and limitations. To help the child make educational plans consist with his/her abilities, interests and goals. To enable the student to know detail about the subject and courses offered.

To assist the student in making satisfactory progress in various school/ college subjects. To help the child to adjust with the schools, its rules, regulations, social life connected with it. To help the child in developing good study habits. To help the child to participate in out of class educational activities in which he can develop leadership and other social qualities

\section{Vocational Guidance:}

You know that bread and butter aimsll is one of the main aims of education. Due to advancement in science and technology and consequent charges in industry and occupations have been emerged. There are thousands of specialized jobs/ occupations. In this context, there is a great need for vocational guidance.

Vocational guidance is a process of assisting the individual to choose an occupation, prepare for it, and enter upon it and progress in it. It is concerned primarily with helping individuals make decisions and choices involved in planning a future and building a career. The purpose behind assisting the youth to choose, prepare, enter and progress in a vocation is the optimum growth of the individual.

Some of the aims and objectives of vocational guidance are: 
Assisting pupil to discover his/her own abilities and skills to feet them into general requirements of the occupation under consideration. Helping the individual to develop an attitude towards work that will dignify whatever type of occupation s/he may wish to enter. Assisting the individual to think critically about various types of occupations and to learn a technique for analyzing information about vocations. Assisting pupils to secure relevant information about the facilities offered by various educational institutions engaging in vocational training.

Social Guidance: We are social animals. But social relationships constitute a problem area for most of the students. School/educational institution is a miniature society and pupil from different socio-economic status, linguistic and socio - cultural background read there.

Students some time may face problems in adjustment and social relationship. It is very important that the students to be helped in acquiring in feeling of security and being accepted by the group in developing social relationship and in becoming tolerant towards others. This is the task of social guidance. Formally social guidance can be given by educational institutions whereas informal guidance may be provided by Family, religious institutions, Media etc.

Moral Guidance: Moral values occupy an important place in our life. Some times due to influence of diverse factors students tell lies and indulge in undesirable practices. Moral guidance helps in bringing these students in to proper track and help in their all round development.

Health Guidance: Health is regarded as the wealth. Total health i.e. preventive and curative is the goal of health guidance. The health guidance may be a cooperative effort of Principal, Doctors, Counsellor/psychologist,

Teachers, Students and parents. For promoting preventive care the conditions of school hostel, canteen needs to be checked. Similarly health education through formal classes and information is essential in school education stages. In the present day the concern of health guidance also pertains to guidance

\section{Assumptions}

$>$ The guidance needs and the behaviour of secondary school students are not as they were in the previous years.

$>$ The students of secondary schools are having indifference over most of the important things which they must adhere.

$>$ The guidance needs for the present day students are not upto the standards of expectations.

$>$ The guidance needs of the students has straight impact over their academic achievement

\section{Statement Of The Problem}

A Study on Guidance Needs of Urban and Rural Adolescence In Relation to the Home Environment

\subsection{Variables Of The Study}

\section{i. Dependent Variables}

Guidance needs of urban and rural adolescence in relation to the home environment

\section{ii. Independent Variable}

1. Gender (Male/female)

2. Age

3. Class

4. Type of institution

5. Location of institution

6. Location of residence

7. Family type (Joint family/ Nuclear family)

8. Parents education
i. $\quad$ Father (Educated / Uneducated)
ii. $\quad$ Mother (Educated/ Uneducated)

\section{Objectives Of The Study}

1. To identify the guidance needs of secondary school students.

2. To study the guidance needs (physical, social, psychological, educational and vocational) of secondary school students on the basis of gender and location of their residence.

3. To compare the guidance needs (physical, social, psychological, educational and vocational) of secondary school students on the basis of gender and location of their residence.

4. To explore the needs of students of secondary schools with the their expectations.

5. To find out the level of teachers/parents' expectations over the needs of students behaviour.

6 . To find out the changing culture and conduct behaviour of students 
7. To measure the impact of students habits and their needs over their educational standards.

\section{Hypotheses Of The Study}

$\mathrm{H}_{01}$ - There is no significant difference between the mean scores of guidance needs of urban and rural adolescence in relation to the home environment with respect to gender.

$\mathrm{H}_{02}$ - There is no significant difference between the mean scores of guidance needs of urban and rural adolescence in relation to the home environment with respect to age.

$\mathrm{H}_{03}$ - There is no significant difference between the mean scores of guidance needs of urban and rural adolescence in relation to the home environment with respect to class.

$\mathrm{H}_{04}$ - There is no significant difference between the mean scores of guidance needs of urban and rural adolescence in relation to the home environment with respect to Government and Aided school.

$\mathrm{H}_{05}$ - There is no significant difference between the mean scores of guidance needs of urban and rural adolescence in relation to the home environment with respect to Government and Private / Self financing school. $\mathrm{H}_{06}$ - There is no significant difference in the mean scores of guidance needs of urban and rural adolescence in relation to the home environment with respect to Aided and Private / Self financing school.

$\mathrm{H}_{07}$ - There is no significant difference in the mean scores of guidance needs of urban and rural adolescence in relation to the home environment with respect to location of school.

$\mathrm{H}_{08}$ - There is no significant difference between the mean scores of guidance needs of urban and rural adolescence in relation to the home environment with respect to education of father.

$\mathrm{H}_{09}$ - There is no significant difference between the mean scores of guidance needs of urban and rural adolescence in relation to the home environment with respect to mother's education.

$\mathrm{H}_{010}$ - There is no significant difference between the mean scores of guidance needs of urban and rural adolescence in relation to the home environment with respect to place of residence.

$\mathrm{H}_{011}$ - There is no significant difference between the mean scores of guidance needs of urban and rural adolescence in relation to the home environment with respect to type of family.

\section{Delimitations Of The Study}

1. The respondents were taken the survey with the help of their class teachers during their class hours may feel some pressure to respond correctly and exactly.

2. Since the respondents were secondary school students which may hindered them from taking the survey seriously, or they may find it indifferently.

3. The study was conducted only to secondary school students.

\section{Research Method}

\section{Methodology}

The investigator adopted the quantitative survey method of research to study the guidance needs of students of secondary school level. Survey research is a procedure in which information is systematically collected from a population through some form of direct solicitation such as administering questionnaire or schedule.

The information of what exists is gathered by studying and analyzing important aspects of present situation. The information of what we want is obtained by clarifying goals, and objectives possibly through a study of the conditions existing else where or what experts consider to be desirable.

\section{Population}

The population is the totality of all possible values, measurements, of a particular characteristic for a specific group or objects. And a sample is part of a population selected according to some rule or plan. The larger group of individuals represented by the sample is called "Population". The usual purpose of educational research is to learn something about a large group of people by studying much smaller group of people. The large group to learn about is called a population.

The population is also called universe, that means the members of a real or hypothetical set of people, events or objects to which the research intents to generalize the results of research study. In this study, all students of secondary schools in Namakkal District are called population.

Accessible population of the study was students from randomly selected secondary schools in Rasipuram, NAMAKKAL District. 300 students from secondary schools were selection for this study.

\section{Sample}

A sample is a small portion of a population selected for analysis. By observing the sample, certain inferences may be made about the population. Sampling means selecting a given number of people's defined 
populations, as representative of that population. The researcher adopted simple random sampling method for the selection of samples.

\section{Distribution Of Sample}

The samples were classified into different categories such as Gender, Age, Class, type of institution, Location of the institutions, location of residence, monthly income of the family and type of family.

Distribution of Samples based on schools

\begin{tabular}{|l|l|l|l|}
\hline Sl.No & Name of the School & No of Respondents & Percentage \\
\hline 1 & \multicolumn{1}{|c|}{ Govt. Hr. Sec. School, Rasipuram } & 90 & $30 \%$ \\
\hline 2 & Girls Hr. Sec. School, Rasipuram & 90 & $30 \%$ \\
\hline 3 & kongunadu Matric Hr. Sec. School, Namakkal & 50 & $17 \%$ \\
\hline 4 & PGP Matriculation Hr.Sec. School, /Namakkal & $23 \%$ \\
\hline
\end{tabular}

\section{Description Of The Research Tools}

Questionnaire was constructed and all the questions have a focus on "guidance needs of urban and rural adolescence in relation to home environment" of secondary school students, both in English and in Tamil for the present trend of educational set up. There were forty one questions in this questionnaire which are in five point rating scale.

\section{Validity Of The Tools}

For the sake of validity the Tools - questionnaires, the composition of questions included in the instruments was tested and validated, through the experts in the field of education. So far as the content validity of measuring instrument was concerned it was checked by different educational experts. They carefully checked its organization and gave some suggestions about its modification and then it came to its final shape.

The questionnaire was also field tested through parents whose children are studying in secondary level. The alpha value of the questionnaire was 0.73 .

\section{Reliability Of The Tools}

The questionnaire was both in English and in Tamil and this was administered on 25 samples. The results of this study were analyzed, and in order to find out the internal consistency of the instrument. The data obtained from the respondents were entered and the split half method validation was 0.81 .

\section{Data Collection}

The researchers personally visited all the educational institutions and after personally met the heads of the institution, after getting the permission by explaining the necessity of data collection, the students in the respective schools were personally met. More than 320 responses were received from the respondents, from which all the uncompleted responses were rejected and 300 responses were selected for analysis.

\section{Hypothesis - 1}

\section{Statistical Analysis Of Hypotheses}

$\mathrm{H}_{01}$ - There is no significant difference between the mean scores of guidance needs of urban and rural adolescence in relation to the home environment with respect to gender.

\begin{tabular}{|l|l|l|l|l|l|l|}
\hline Gender & No. of respondents & Mean & SD & $\begin{array}{l}\text { Calculated 't' } \\
\text { value }\end{array}$ & $\begin{array}{l}\text { Table } \\
\text { Value }\end{array}$ & $\begin{array}{l}\text { Significance at } \\
\text { Level }\end{array}$ \\
\cline { 1 - 3 } & 145 & 136 & 17.32 & \multirow{2}{*}{1.22} & \multirow{2}{*}{1.96} & \multirow{2}{*}{ Not Significant } \\
\hline Female & 155 & 142 & 17.46 & & \\
\hline
\end{tabular}

\section{Interpretation:}

The obtained ' $t$ ' value 1.22 is lesser than the critical value of 1.96 at 0.05 level. This indicates that there is no significant difference between guidance needs of urban and rural adolescence in relation to the home environment with respect to gender.

Hence the above hypothesis is accepted. There is no significant difference between the mean scores of guidance needs of urban and rural adolescence in relation to the home environment with respect to gender.

\section{Hypothesis - 2}

$\mathrm{H}_{02}$ - There is no significant difference between the mean scores of guidance needs of urban and rural adolescence in relation to the home environment with respect to age.

\begin{tabular}{|l|l|l|l|l|l|l|}
\hline Age & No. of respondents & Mean & SD & $\begin{array}{l}\text { Calculated ‘t' } \\
\text { value }\end{array}$ & $\begin{array}{l}\text { Table } \\
\text { Value }\end{array}$ & $\begin{array}{l}\text { Significance at } \\
\text { Level }\end{array}$ \\
\hline Below 15 yrs & 177 & 146 & 17.45 & \multirow{2}{*}{1.23} & \multirow{2}{*}{1.96} & Not Significant \\
\hline Above 15 yrs & 123 & 150 & 17.64 & & \\
\hline
\end{tabular}




\section{Interpretation:}

The obtained ' $t$ ' value 1.23 is smaller than the critical value of 1.96 at 0.05 level. This indicates that there is no significant difference between guidance needs of urban and rural adolescence in relation to the home environment with their age. Hence the above hypothesis is accepted.

There is no significant difference between the mean scores of guidance needs of urban and rural adolescence in relation to the home environment with respect to age.

\section{Hypothesis -3}

$\mathrm{H}_{03}$ - There is no significant difference between the mean scores of guidance needs of urban and rural adolescence in relation to the home environment with respect to Class.

\begin{tabular}{|l|l|l|l|l|l|l|}
\hline Class & $\begin{array}{l}\text { No. of } \\
\text { respondents }\end{array}$ & Mean & SD & $\begin{array}{l}\text { Calculated 't' } \\
\text { value }\end{array}$ & $\begin{array}{l}\text { Table } \\
\text { Value }\end{array}$ & $\begin{array}{l}\text { Significance at } 0.05 \\
\text { Level }\end{array}$ \\
\cline { 1 - 4 } $8^{\text {th }}$ & 100 & 142 & 17.56 & 1.55 & 1.96 & Not Significant \\
\hline $9^{\text {th }}$ & 102 & 147 & 17.59 & 1.55 & \\
\hline
\end{tabular}

\section{Interpretation:}

The obtained ' $t$ ' value 1.55 is lesser than the critical value of 1.96 at 0.05 level. This indicates that there is no significant difference between guidance needs of urban and rural adolescence in relation to the home environment with respect to class. Hence the above hypothesis is accepted.

There is no significant difference between the mean scores of guidance needs of urban and rural adolescence in relation to the home environment with respect to class.

\section{Hypothesis -4}

$\mathrm{H}_{04}$ - There is no significant difference between the mean scores of guidance needs of urban and rural adolescence in relation to the home environment with respect to Government and Aided school.

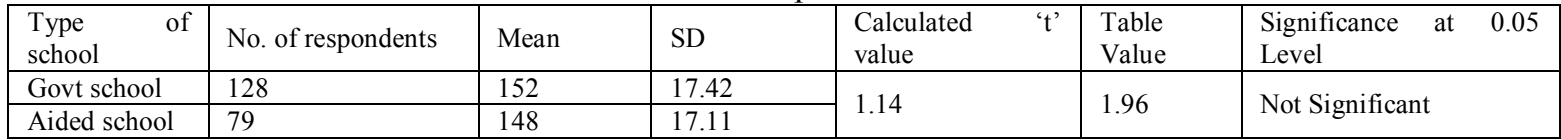

\section{Interpretation:}

The obtained ' $t$ ' value 1.14 is lesser than the critical value of 1.96 at 0.05 level. This indicates that there is no significant difference between guidance needs of urban and rural adolescence in relation to the home environment with respect to government and Aided school. Hence the above hypothesis is accepted.

There is no significant difference between the mean scores of guidance needs of urban and rural adolescence in relation to the home environment with respect to Government and Aided school.

\section{Hypothesis -5}

$\mathrm{H}_{05}$ - There is no significant difference between the mean scores of guidance needs of urban and rural adolescence in relation to the home environment with respect to Government and Private school.

\begin{tabular}{|l|l|l|l|l|l|l|}
\hline Type of school & No. of respondents & Mean & SD & $\begin{array}{l}\text { Calculated 't' } \\
\text { value }\end{array}$ & $\begin{array}{l}\text { Table } \\
\text { Value }\end{array}$ & $\begin{array}{l}\text { Significance at } \\
\text { Level }\end{array}$ \\
\hline Govt school & 128 & 152 & 17.42 & 0.05 & Not Significant \\
\hline Private & 93 & 149 & 17.12 & 0.67 & 1.96 & (2) \\
\hline
\end{tabular}

\section{Interpretation:}

The obtained ' $t$ ' value 0.67 is lesser than the critical value of 1.96 at 0.05 level. This indicates that there is no significant difference between guidance needs of urban and rural adolescence in relation to the home environment with respect to Government and private school. Hence the above hypothesis is accepted.

There is no significant difference between the mean scores of guidance needs of urban and rural adolescence in relation to the home environment with respect to Government and Private school.

\section{Hypothesis - 6}

$\mathrm{H}_{06}$ - There is no significant difference in the mean scores of guidance needs of urban and rural adolescence in relation to the home environment with respect to location of school.

\begin{tabular}{|l|l|l|l|l|l|l|l|}
\hline Location & No. of respondents & Mean & SD & $\begin{array}{l}\text { Calculated 't' } \\
\text { value }\end{array}$ & $\begin{array}{l}\text { Table } \\
\text { Value }\end{array}$ & $\begin{array}{l}\text { Significance at } 0.05 \\
\text { Level }\end{array}$ \\
\cline { 1 - 4 } Rural & 140 & 148 & 17.12 & 2.07 & 1.96 & Significant \\
\hline Urban & 160 & 155 & 17.46 & 2.07 & \\
\hline
\end{tabular}




\section{Interpretation:}

The obtained ' $t$ ' value 2.07 is greater than the critical value of 1.96 at 0.05 level. This indicates that there is a significant difference between guidance needs of urban and rural adolescence in relation to the home environment with respect to location of school. Hence the above hypothesis is not accepted.

There is a significant difference in the mean scores of guidance needs of urban and rural adolescence in relation to the home environment with respect to location of school.

\section{Hypothesis -7}

$\mathrm{H}_{07}$ - There is no significant difference between the mean scores of guidance needs of urban and rural adolescence in relation to the home environment with respect to education of parents.

\begin{tabular}{|l|l|l|l|l|l|l|}
\hline Education of parents & No. of respondents & Mean & SD & $\begin{array}{l}\text { Calculated ' } t \text { ' } \\
\text { value }\end{array}$ & $\begin{array}{l}\text { Table } \\
\text { Value }\end{array}$ & $\begin{array}{l}\text { Significance at } 0.05 \\
\text { Level }\end{array}$ \\
\cline { 1 - 3 } Educated & 54 & 148 & 17.68 & 1.54 & 1.96 & Not Significant \\
\cline { 1 - 2 } & 242 & 153 & 17.82 & & \\
\hline
\end{tabular}

\section{Interpretation:}

The obtained ' $t$ ' value 1.54 is lesser than the critical value of 1.96 at 0.05 level. This indicates that there is no significant difference between guidance needs of urban and rural adolescence in relation to the home environment with respect to education of father. Hence the above hypothesis is accepted.

There is no significant difference between the mean scores of guidance needs of urban and rural adolescence in relation to the home environment with respect to education of father.

\section{Hypothesis -8}

$\mathrm{H}_{08}$ - There is no significant difference between the mean scores of guidance needs of urban and rural adolescence in relation to the home environment with respect to place of residence.

\begin{tabular}{|l|l|l|l|l|l|l|}
\hline $\begin{array}{l}\text { Place } \\
\text { residence }\end{array}$ & No. of respondents & Mean & SD & $\begin{array}{l}\text { Calculated 't' } \\
\text { value }\end{array}$ & $\begin{array}{l}\text { Table } \\
\text { Value }\end{array}$ & $\begin{array}{l}\text { Significance at } \\
\text { Level }\end{array}$ \\
\hline Rural & 128 & 149 & 17.46 & 1.43 & 1.96 & Not Significant \\
\hline Urban & 172 & 154 & 17.48 & 1.43 & 1.96 \\
\hline
\end{tabular}

\section{Interpretation:}

The obtained ' $t$ ' value 1.43 is lesser than the critical value of 1.96 at 0.05 level. This indicates that there is no significant difference between guidance needs of urban and rural adolescence in relation to the home environment with respect to location of residence.

There is no significant difference between the mean scores of guidance needs of urban and rural adolescence in relation to the home environment with respect to place of residence.

\section{Hypothesis - 9}

$\mathrm{H}_{09}$ - There is no significant difference between the mean scores of guidance needs of urban and rural adolescence in relation to the home environment with respect to type of family.

\begin{tabular}{|l|l|l|l|l|l|l|}
\hline $\begin{array}{l}\text { Type of } \\
\text { family }\end{array}$ & No. of respondents & Mean & SD & $\begin{array}{l}\text { Calculated 't' } \\
\text { value }\end{array}$ & $\begin{array}{l}\text { Table } \\
\text { Value }\end{array}$ & $\begin{array}{l}\text { Significance at } \\
\text { Level }\end{array}$ \\
\cline { 1 - 3 } Joint & 24 & 145 & 17.33 & 1.84 & 1.96 & Not Significant \\
\hline Nuclear & 276 & 150 & 17.45 & 1.84 & \\
\hline
\end{tabular}

\section{Interpretation:}

The obtained ' $t$ ' value 1.84 is lesser than the critical value of 1.96 at 0.05 level. This indicates that there is no significant difference between guidance needs of urban and rural adolescence in relation to the home environment with respect to type of family. Hence the above hypothesis is accepted.

There is no significant difference between the mean scores of guidance needs of urban and rural adolescence in relation to the home environment with respect to type of family.

\section{Findings}

\section{Findings and Conclusion}

Out of 300 respondents, $52 \%$ (155) of the respondents are female and $48 \%$ (145) of the respondents are male.

* Out of 300 respondents, $41 \%$ (123) of the respondents have completed 15 years of age, followed by $31 \%$ (92) of the respondents have completed 14 years of age and $28 \%(85)$ of the respondents have completed 13 years of age.

* Out of 300 respondents, $34 \%$ (102) of the respondents are studying in $9^{\text {th }}$ standard, $33 \%$ of the respondents are studying in $8^{\text {th }}$ Standard and $10^{\text {th }}$ Standard each. 
* Out of 300 respondents, $43 \%$ (128) of the respondents are studying in Government schools, $31 \%$ (93) of the respondents are studying in Private schools and 26\% (79) of the respondents are studying in Aided schools.

* Out of 300 respondents, $50 \%$ (150) of the respondents are studying in schools, which are located in urban area and 50\% (150) of the respondents are studying in schools which are located in rural area.

* Out of 300 respondents, $29 \%$ of the respondents' fathers have completed higher secondary course and other educational qualifications. $23 \%$ of the respondents' fathers have completed high school education, $10 \%$ (30) of the respondents' fathers have completed degree and $9 \%$ (28) of the respondents' fathers were illiterates.

* Out of 300 respondents, $29 \%$ (86) of the respondents' mothers are having other educational qualifications, $23 \%$ of the respondents' mothers are having high school and higher secondary qualification each, $15 \%$ (46) of the respondents' mother are illiterate and 10\% (30) of the respondents' mothers are having degree qualification.

* Out of 57\% (172) of the respondents are residing in urban areas and $43 \%$ (128) of the respondents are residing in rural areas.

- The above table shows that monthly income of the respondents' family. Out of 300 respondents, $41 \%$ (122) of the respondents' family income is below Rs.10000/-, 33\% of the respondents' family income is between Rs. 10000 - Rs. 15000 and 27\% (80) of the respondents' family income is above Rs. 15000.

* Out of 300 respondents, 92\% (276) of respondents are living in nuclear family settings and $8 \%$ (24) of the respondents are living in joint family setup.

\section{Findings of Statistical Analysis}

* There is no significant difference between the mean scores of guidance needs of urban and rural adolescence in relation to the home environment with respect to gender.

* There is no significant difference between the mean scores of guidance needs of urban and rural adolescence in relation to the home environment with respect to age.

* There is no significant difference between the mean scores of guidance needs of urban and rural adolescence in relation to the home environment with respect to class.

* There is no significant difference between the mean scores of guidance needs of urban and rural adolescence in relation to the home environment with respect to Government and Aided school.

* There is no significant difference between the mean scores of guidance needs of urban and rural adolescence in relation to the home environment with respect to Government and Private school.

* There is a significant difference in the mean scores of guidance needs of urban and rural adolescence in relation to the home environment with respect to location of school.

* There is no significant difference between the mean scores of guidance needs of urban and rural adolescence in relation to the home environment with respect to education of parents.

* There is no significant difference between the mean scores of guidance needs of urban and rural adolescence in relation to the home environment with respect to place of residence.

* There is no significant difference between the mean scores of guidance needs of urban and rural adolescence in relation to the home environment with respect to type of family.

\section{Conclusion}

In schools and in wider society there is considerable discussion and anxiety about young people's guidance needs academically and non academically. Many teaching staff and parents staff are of the opinion that guidance needs of young students has rising up. It is worth looking as some of the factors that may be shaping that perceived change. There is greater realisation, too, of the rights of students to be more involved in many of the decisions that involve their lives.

If one now expect to consult with students when we conduct special needs reviews. School councils are being given substantial resources. It is quite common to find students represented on governing bodies.

All this reflects an increasingly 'rights-based consciousness' in society at large. Some adults find it difficult to adjust to this shift in relationships. Some discipline policies seem to have been written as if nothing has changed.

In some schools students have been trained as observers to give feedback to staff on their teaching performance. Just imagine the profound change in teacher-student relationships that such a practice involves. So a prime objective of guidance is to be created the positive conditions for a new style of guidance and learning, in which ultimately self-directed learning may flourish.

The nature of childhood is changing. The techno-cultural revolution of the last decade has created a society where children and adults share much more of a common culture, so that many of the distinctions between adult and child roles have blurred. On the positive side children are more inclined to question, to be 
more assertive, and to have a kind of 'digital intelligence' that is not available to the older generation. On the other hand, they can become more individualistic and less inclined to make effort at the behest of an adult. Some children at the extreme end of this spectrum can seem impossible to manage. So we may often see in our schools a mismatch between the teachers' expectations of how they believe a child should behave and the students' selfconcept - their actual beliefs and attitudes about their role as learners.

We need a central concept to help us understand these changes, and to give purpose to guidance. What we are experiencing in some of today's schools is that a 'traditional' approach to discipline, where we tell children what behaviour we require and then expect them to follow those rules, just doesn't work too well. As well as keeping order in our schools and teaching the curriculum, teachers and parents have to face the challenge of teaching and negotiating responsible to social and school guidance needs.

\section{Bibliography}

[1]. Agrawal,R(2006) Educational,Vocational Guidance and Counselling,New Delhi,Sipra Publication

[2]. Bhatnagar,A AND Gupta,N(1999).Guidance and Counselling: A theoretical Approach(Ed),New Delhi,Vikash Publishing House

[3]. Jones, A.J.(19510.Principles of Guidance and Pupil Personnel work,New Y ork,MiGraw Hill

[4]. Kochhar, S.K (1985): Educational and Vocational Guidance in Secondary Schools,New Delhi,Strling Publisher NCERT (2008).Introduction to Guidance,Module -1,DEPFE,New Delhi

[5]. Agarwal J. C. (1985) Educational Vocational Guidance and Counselling, Doaba House New Delhi.

[6]. Bernard Harold W. (1969) Principles of Guidance - Allied Publishers Pvt. Ltd. New Delhi.

[7]. Bernard and Fullmer (1972) The School Counsellor Consultant Boston, Houghton Mifflin Company.

[8]. Bhati S. S. (1979) Jobs Careers and Personality New Delhi, Indian Institute of International Understanding

[9]. Borrow Harold W. (1973) Career Guidance for a New Age Boston, Houghton Miffing Company.

[10]. Chibber S. K. (1999) Guidance and Counselling Common Wealth Publishers, New Delhi

[11]. Drummond, R. J. and Ryan, C. W. Career Counselling And Development Appraoch Prentice hall of India, New Delhi.

[12]. Gothard, W. P. : (1985) Vocational Guidance Theory and Practice, Croom Helm London.

[13]. Hoppak R. (1976) Occupational Information : Where to Get and How to Use in Counselling and Teaching, Mc Graw Hills Publications New York

[14]. Jaffrey A. Kotler and Elien Kothar, (1993) Teacher as a Counsellor, Sage Publication London.

[15]. Jones, J. A., (1979) Principles of Guidance, Mc Graw Hill New York.

[16]. Kemp Gratton (1978) Foundations of Group Counselling Prentice Hall of India Pvt. Ltd. New Delhi.

[17]. Kochhar, S. K., (1980) Guidance and Counselling, Sterling Publishers, New Delhi.

[18]. Kevin, Anglo (1987) Vocationalizing Education an International Perspective Pergamon Press, Oxford London

[19]. Mosher, Carle, Kehas (Ed) (1972) Guidance on Examinations, Harcourt, Brace \& Wond.

[20]. Mc Daniel. Henry (1956) Guidance in Modern School. Holt, Rinchart and Winston New York.

[21]. Nanda, S. K. and Sharma S., (1992) Fundamentals of Guidance, Chandigarh. 